\title{
Efficacy and safety of delapril/indapamide compared to different ACE-inhibitor/hydrochlorothiazide combinations: a meta-analysis
}

This article was published in the following Dove Press journal:

International Journal of General Medicine

28 August 2012

Number of times this article has been viewed

\author{
Maria Circelli' \\ Gabriele Nicolini' \\ Colin G Egan ${ }^{2}$ \\ Giovanni Cremonesi' \\ 'Chiesi Farmaceutici, Direzione \\ Medica, Parma, Italy; ${ }^{2}$ Primula \\ Multimedia, Pisa, Italy
}

\begin{abstract}
The main objective of this meta-analysis was to compare the efficacy of the combination of delapril and indapamide (D+I) to different angiotensin-converting enzyme inhibitor (ACEi) plus hydrochlorothiazide (HCTZ) combinations for the treatment of mild-to-moderate hypertension. A secondary objective was to examine the safety of these two combinations. Studies comparing the efficacy of D+I to ACEi+HCTZ combinations in hypertensive patients and published on computerized databases (1974-2010) were considered. Endpoints included percentage of normalized patients, of responders, change in diastolic and systolic blood pressure (DBP/SBP) at different time-points, percentage of adverse events (AEs), and percentage of withdrawal. Four head-to-head randomized controlled trials (D+I-treated, $n=643$; ACEi+HCTZ-treated, $n=629$ ) were included. Meta-analysis indicated that $\mathrm{D}+\mathrm{I}-$ treated patients had a higher proportion with normalized blood pressure $(P=0.024)$ or responders $(P=0.002)$ compared to ACEi+HCTZtreated patients. No difference was observed between treatments on absolute values of DBP and SBP at different time-points. Although the rate of patients reporting at least one AE was similar in both groups (10.4\% versus $9.9 \%)$, events leading to study withdrawal were lower in the $\mathrm{D}+\mathrm{I}$ group versus the ACEi+HCTZ group ( $2.3 \%$ versus $4.8 \%$, respectively; $P=0.018$ ). This meta-analysis suggests that treatment with $\mathrm{D}+\mathrm{I}$ could provide a higher proportion of normalized or responder patients with good tolerability compared to ACEi+HCTZ combinations.
\end{abstract}

Keywords: meta-analysis, hypertension, ACE inhibitor, diuretic, delapril, indapamide

\section{Introduction}

Hypertension is a major risk factor for stroke and cardiovascular disease (CVD) ${ }^{1-4}$ and current estimates indicate that high blood pressure (BP) affects approximately $25 \%$ of the general population. ${ }^{5,6}$ Unfortunately, worldwide BP control in hypertensive patients is far from optimal, probably due to poor adherence to both antihypertensive drug therapies and lifestyle recommendations. ${ }^{7,8}$ Although many factors contribute to poor compliance, the side-effect profile of antihypertensive drugs is perhaps the most influential. ${ }^{9}$ It is recognized that monotherapy does not adequately control BP in up to $50 \%$ of patients. ${ }^{1-4}$ Meanwhile, fixed combination therapy with different classes of drugs is increasingly used as an alternative. In light of the need to attain BP goals, both European guidelines and the Seventh Report of the Joint National Committee on the Prevention, Detection, Evaluation, and Treatment of High Blood Pressure (JNC-7) report now recommend combination therapy, especially when monotherapy fails to reach BP goals or in patients at high cardiovascular (CV) risk. ${ }^{1-3}$ Fixed combination therapy offers several advantages over monotherapy and these include: improved antihypertensive efficacy and reduced time required to attain BP targets. ${ }^{1}$
Correspondence: Maria Circelli Chiesi Farmaceutici S.p.A., via Palermo 26/A, 43I00 Parma, Italy

Tel +3905 2I2791। 5

Fax +390521279592

Email m.circelli@chiesi.com 
Furthermore, since lower doses of these agents are required to obtain the same efficacy, patients also experience fewer side effects. ${ }^{1}$ Moreover, greater levels of compliance are achieved with fixed combination therapy compared to a combination of two or more drugs, due to the reduced number of tablets taken. ${ }^{1}$ This is particularly important in patients with comorbid conditions that require multiple medications. Currently, a wide range of fixed-dose combination antihypertensive therapies are available. ${ }^{1-4}$ According to a position paper on behalf of the American Society of Hypertension, these preferred two-drug combinations include angiotensin-converting enzyme inhibitors (ACEi) plus diuretic; angiotensin-receptor blockers plus diuretic; beta-blockers plus diuretic; and calcium channel blockers plus ACEi ${ }^{10}$ Many fixed-combination antihypertensive drugs contain a diuretic in combination with another diuretic or a drug from a different class. Combining a (low-dose) ACEi with a diuretic is recognized as being highly effective, since these two drug classes exhibit different mechanisms of action that result in an additive antihypertensive effect. ${ }^{11,12}$ The fixed combination of the ACEi delapril and the diuretic indapamide is particularly effective. Besides their additive antihypertensive effects, the delapril and indapamide $(\mathrm{D}+\mathrm{I})$ combination are also recognized for their beneficial pleiotropic effects. ${ }^{11-15}$

Indapamide is a nonthiazide chlorosulphonamide indole derivative, which is characterized by long-acting hypotensive effects and minimal diuretic activity when administered at the recommended doses. ${ }^{16,17}$ This is also a lipophilic agent, allowing it to be rapidly absorbed from the gastrointestinal tract with a half-life of approximately 18 hours, permitting once-daily dosing. ${ }^{18,19}$ Indapamide also preferentially binds to vascular smooth muscle cells, inducing vasodilatation. ${ }^{19}$ Furthermore, it appears that the antihypertensive and diuretic effects of indapamide occur at different doses. The antihypertensive actions occur at subdiuretic doses and are likely due to the drug's direct vascular effect, which are independent of its diuretic action. ${ }^{11}$ Delapril, on the other hand, is a nonsulphydryl ACEi with high specificity for the C-terminal of the peptide located in the vasculature and myocardium. ${ }^{20,21}$ Like indapamide, delapril is also highly lipophilic, and is recognized to inhibit vascular ACE more potently than either captopril or enalapril. ${ }^{20,22}$

Previous studies have demonstrated that the antihypertensive action of the $\mathrm{D}+\mathrm{I}$ combination is greater than either drug administered as monotherapy, suggesting an additive effect. ${ }^{23,24}$ Although several clinical studies have examined the efficacy and safety of the D+I combination to placebo, ${ }^{18,23-26}$ only a few head-to-head clinical trials have been under- taken. ${ }^{27-30}$ Although efficacy data emerging from these trials would appear to slightly favor the use of the D+I combination over ACEi + hydrochlorothiazide (HCTZ) combinations, ${ }^{27-29}$ no definitive evidence is currently available that can verify this. To address this clinically relevant issue, we have therefore performed a meta-analysis of head-to-head randomized controlled trials (RCTs), to compare the efficacy and safety of the fixed combination D+I compared to different ACEi and HCTZ combinations in hypertensive patients.

\section{Methods}

\section{Search and selection}

A literature search was performed only on articles published in peer-reviewed journals to improve the methodological quality of studies examined and conclusions drawn. A systematic electronic search was performed using the following databases: PubMed/Medline, INIST, (Institut de l'Information Scientifique et Tecnique). Science Direct, and Google Scholar. Published clinical studies comparing the efficacy of D+I to ACEi+HCTZ combinations (October 1974-July 2011) were considered for analysis. Inclusion criteria were: RCT of at least 1-month duration; head-to-head trials comparing efficacy of D+I to ACEi+HCTZ combinations; patients with mild-to-moderate hypertension; assessment of systolic and diastolic blood pressure (SBP and DBP); and measurement of side effects. Text words that were applied to the search field included "delapril" and "indapamide" either alone or in combination.

\section{Definition of outcome measures}

Since outcome measures were similar for all four studies ${ }^{27-30}$ included in the meta-analysis, we considered the definitions used in each study as follows: normalized patients were defined as showing a reduction in sitting DBP $\leq 90 \mathrm{mmHg}$ at the 4-week visit ${ }^{27,29}$ or at the end of the 12-week period of treatment. ${ }^{28,30}$ Responder patients were defined as: (a) showing a reduction in sitting DBP of $15 \mathrm{mmHg}$ after 1 month of treatment, compared to baseline values; ${ }^{27}$ (b) showing a reduction in sitting DBP of $10 \mathrm{mmHg}$ compared to baseline values or DBP $\leq 90 \mathrm{mmHg}$ after 12 weeks of treatment; ${ }^{28,30}$ or (c) demonstrating a reduction in sitting DBP of $10 \mathrm{mmHg}$ from baseline after 1 month of treatment. ${ }^{29}$ Leonetti ${ }^{27}$ reported two definitions of patient responders: (a) patients with reduction in sitting DBP of $15 \mathrm{mmHg}$ and (b) a second, wider definition, which also included the definition of normalized patients. In this case, the difference between treatments was greater so we chose the former definition, which was more conservative. The effect of treatment on both sitting SBP and DBP at 
30 days and at the final visit (end of study) compared to baseline values was also examined. In studies from Leonetti ${ }^{27}$ and Cremonesi et $\mathrm{al},{ }^{28}$ the variation in both sitting SBP and DBP between visits was estimated graphically. From studies by Rosei and Rizzoni ${ }^{29}$ and Cremonesi et al, ${ }^{30}$ the variation between visits was provided, including $90 \%$ or $95 \%$ confidence intervals $(\mathrm{CI})$.

\section{Statistical analysis}

Data were synthesized using meta-analytic methods described previously. ${ }^{31}$ Denominators used for calculating the response rate of each treatment group were reported in original papers as eligible patients after randomization and according to the intent-to-treat population. The association between exposure (treatments) and binary outcome variables (percentage of normalized, of responders, of AEs, and of withdrawal) were measured by odds ratio (OR). Since ORs were not directly available from the original published studies, they were calculated from tabular data, using the Woolf formula to evaluate the standard error of the $\log (\mathrm{OR}){ }^{32}$ When tabular data were not provided and only response rate was available, the number of responses was calculated by multiplying the response rate by the number of randomized/eligible patients. In the case where a study had zero events in one of the compared groups, the OR for that study was calculated by adding 0.5 events to both groups before proceeding with analysis. To evaluate the effect of this adjustment, a subsequent sensitivity analysis (excluding these studies) was performed. The association between treatment and response rate across the selected trials was computed as pooled OR (POR) with 95\% CI. POR was estimated by pooling study-specific estimates by random effect models fitted using a statistical analysis procedure (Proc Mixed statistical software; SAS Institute Inc, Cary, NC) with maximum likelihood estimate, and graphically represented by forest plot. Heterogeneity of the effect across studies was assessed by the Q statistic, which is distributed as a $\chi^{2}$ statistics. A $P$-value $<0.10$ was used to indicate a lack of homogeneity among effects. $\mathrm{I}^{2}$ statistics were also provided to quantify the percentage of total variation across studies attributable to heterogeneity, rather than by chance alone. ${ }^{33}$ In the case of an $\mathrm{I}^{2}=0$, the heterogeneity due to variation across studies was considered negligible or null and "the random effect model leads to the fixed effect model." ${ }^{31}$ The method of Macaskill was used to assess publication bias. ${ }^{34}$ This consisted of a funnel-plot regression of $\log ($ relative risk) or $\log (\mathrm{OR})$ on the sample size, weighted by the inverse of the pooled variance.
To determine the reduction in DBP, the difference compared to baseline was evaluated. If the confidence interval of the difference over time was reported, the standard deviation was derived by simple calculations, ${ }^{29,30}$ otherwise ${ }^{27}$ it was conservatively estimated by the worst coefficient of variation ( $\mathrm{SD} /$ mean) among the studies that had reported both values. The mean difference between groups, along with its measure of dispersion was then calculated. Statistical analysis was performed using Proc Mixed statistical software. Data are presented as mean \pm SD or CI where indicated. A $P$-value of $<0.05$ was considered statistically significant.

\section{Results}

\section{Trial flow and study characteristics}

Figure 1 shows a flow diagram of the selection process. Our initial search returned 97 distinct results, of which 16 were relevant based on reading their title and abstract. A further 12 studies were excluded because of patient type (not hypertensive patients) or study design (not comparator studies). Four RCTs met the selection criteria and were included in the final meta-analysis. Characteristics of the four studies are presented in Tables 1. All four studies were randomized, multicentric, and conducted between 1997 and 2003 (Table 1). Study duration ranged from 12 weeks

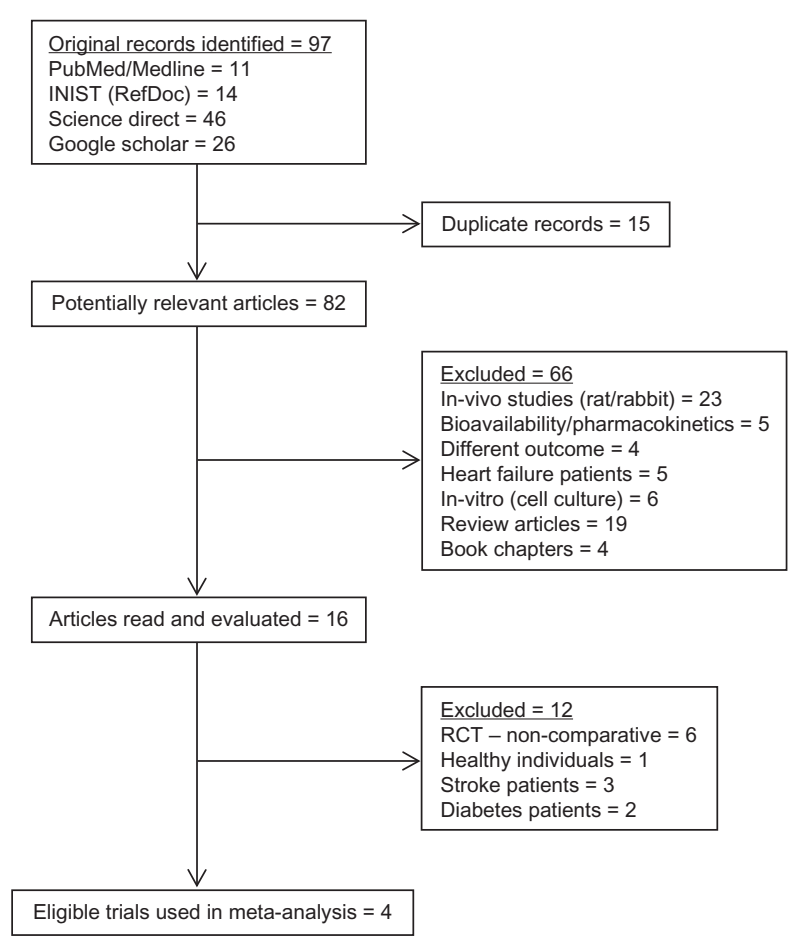

Figure I Selection process for studies included in the meta-analysis. Abbreviations: INIST, Institut de I'Information Scientifique et Technique; RCT, randomized controlled trial. 


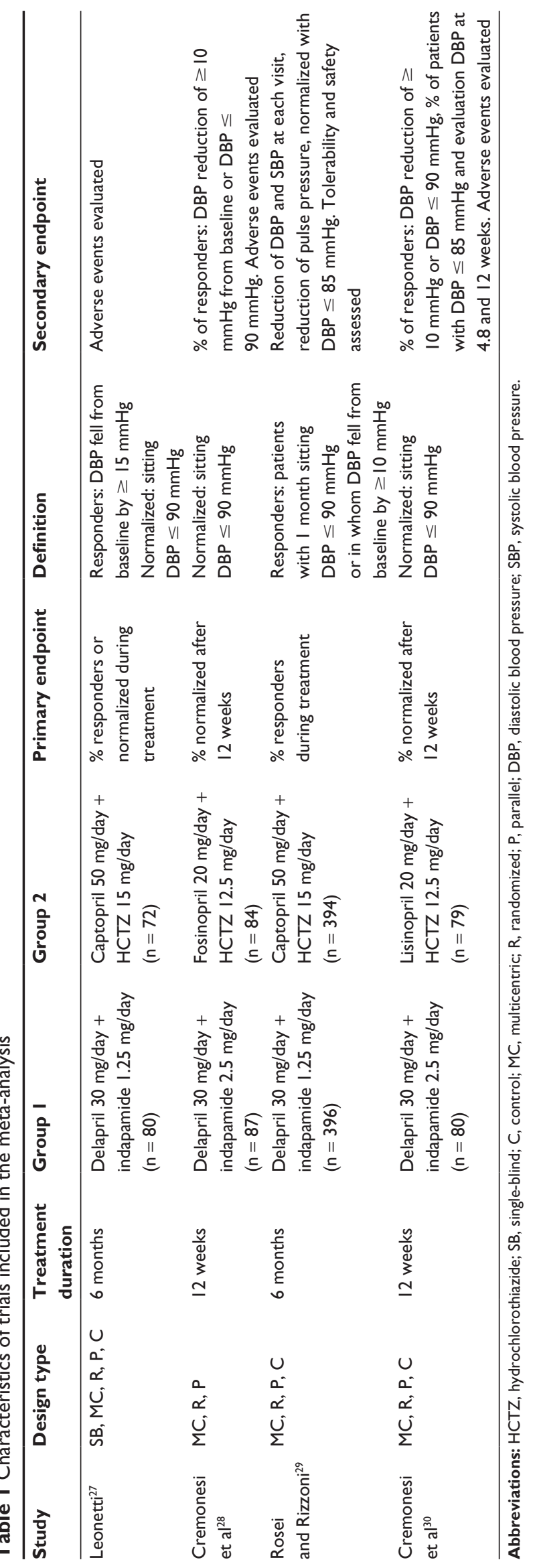

to 6 months and, although doses of D+I were similar in the four studies $(30 \mathrm{mg} /$ day and $1.25-2.5 \mathrm{mg} /$ day for D+I, respectively), doses of the ACEi used with HCTZ varied from $12.5-15 \mathrm{mg}$ /day (Table 1). Primary outcome measures were available for two studies at the 30-day time point and two studies at the 12-week time point.

\section{Patient characteristics}

Baseline clinical characteristics for patients in the four studies are presented in Table 2. Patient numbers were similar in the D+I-treated $(n=643)$ and ACEi+HCTZtreated groups $(n=629)$. Apart from a slightly higher body weight (although clinically insignificant) in patients within the D+I group (78.6 vs $77.1 \mathrm{~kg} ; P<0.037$ ), there was no significant difference between baseline characteristics for the two study groups. At baseline, patients in each of the four studies were diagnosed with mild-to-moderate essential hypertension, reflected in SBP and DBP values presented in Table 2. No differences were observed in SBP, DBP, and demographic characteristics between the two treatment groups.

\section{Efficacy of antihypertensive treatment on blood pressure parameters}

Patients receiving D+I treatment had a higher proportion of being normalized (Figure $2 \mathrm{~A}: \mathrm{OR}=1.32,95 \% \mathrm{CI}$ : $1.04-1.68$; $P=0.024$ ) or being responders (Figure $2 \mathrm{~B}$ : $\mathrm{OR}=1.58,95 \%$ CI: $1.22-2.04 ; P=0.002)$ compared to ACEi+HCTZ-treated patients. In both analyses, the $\mathrm{I}^{2}$ values were $0(\mathrm{Q}=0.77$, $P=0.86$ and $\mathrm{Q}=0.34, P=0.95$, respectively), indicating low heterogeneity between studies.

The DBP reduction over time was similar in the two groups (Figure 3A). Pooling the reported study-specific reduction in the first 4-weeks of treatment showed a variation of $12.9 \mathrm{mmHg}$ and $11.5 \mathrm{mmHg}$ in the D+I- and ACEi+HCTZtreated groups, respectively. The difference between treatment groups just failed to reach statistical significance $(95 \%$ CI: $-0.2-3.0 ; P=0.066)$. Comparing the effect of treatment on $\mathrm{SBP}$ reduction revealed similar results (Figure $3 \mathrm{~B}$ ). The difference between treatment groups in favor of $\mathrm{D}+\mathrm{I}$ was not statistically significant $(95 \% \mathrm{CI}:-1.9-5.7 ; P=0.21)$. Low heterogeneity was detected in the analyses for both DBP $\left(\mathrm{I}^{2}=48.2, \mathrm{Q}=5.8 ; P=0.12\right)$ and $\mathrm{SBP}\left(\mathrm{I}^{2}=60.2, \mathrm{Q}=7.54\right.$; $P=0.06)$ outcome variables, with neither reaching statistical significance.

DBP and SBP reduction over time were also evaluated at the end of the treatment period (Figure 4). Similar to the $\mathrm{BP}$ reduction achieved at 4 weeks, patients treated with the 
Table 2 Baseline demographic and clinical characteristics

\begin{tabular}{|c|c|c|c|c|c|c|c|c|}
\hline Study & $\begin{array}{l}\text { Treatment } \\
\text { group }\end{array}$ & $\begin{array}{l}\text { Age } \\
\text { (years) }\end{array}$ & $\begin{array}{l}\text { Males, \% } \\
\text { (n) }\end{array}$ & $\begin{array}{l}\text { Weight } \\
\text { (kg) }\end{array}$ & $\begin{array}{l}\text { Height } \\
(\mathrm{cm})\end{array}$ & $\begin{array}{l}\text { SBP } \\
(\mathrm{mm} / \mathrm{Hg})\end{array}$ & $\begin{array}{l}\text { DBP } \\
(\mathrm{mm} / \mathrm{Hg})\end{array}$ & $\begin{array}{l}\text { Heart rate } \\
(\text { bpm) }\end{array}$ \\
\hline \multirow[t]{2}{*}{ Leonetti $^{27}$} & $D+I(n=80)$ & $53.4 \pm 7.7$ & $60(48)$ & $82.7 \pm 10$ & $167 \pm 8.3$ & $160.4 \pm 15.5$ & $102.4 \pm 5$ & $76.9 \pm 10$ \\
\hline & $\mathrm{C}+\mathrm{HCTZ}(\mathrm{n}=72)$ & $52.9 \pm 6.6$ & $54.2(39)$ & $83.5 \pm 11.5$ & $166.2 \pm 8.3$ & $159.1 \pm 15.1$ & $102.5 \pm 4.8$ & $76.2 \pm 10.8$ \\
\hline Cremonesi & $D+I(n=87)$ & $55 \pm 11$ & $62.1(54)$ & $82 \pm 12$ & $172 \pm 9$ & $159.9 \pm 11.6$ & $101.8 \pm 5.2$ & $72.6 \pm 8.3$ \\
\hline et $\mathrm{a}^{28}$ & $\mathrm{~F}+\mathrm{HCTZ}(\mathrm{n}=84)$ & $55 \pm 13$ & $54.8(46)$ & $80 \pm 7.8$ & $17 \mid \pm 9$ & $160.7 \pm 11.2$ & $100.9 \pm 5.4$ & $73.9 \pm 8.5$ \\
\hline Rosei & $D+I(n=396)$ & $54 \pm 11$ & $55.8(221)$ & $77 \pm 14$ & $170 \pm 10$ & $160.6 \pm 14.3$ & $101.6 \pm 4.7$ & $74.5 \pm 9.4$ \\
\hline and Rizzoni ${ }^{29}$ & $\mathrm{C}+\mathrm{HCTZ}(\mathrm{n}=394)$ & $54 \pm 11$ & $52.3(206)$ & $75 \pm 14$ & $170 \pm 10$ & $160.1 \pm 14.2$ & $101 \pm 4.8$ & $73.9 \pm 8.8$ \\
\hline Cremonesi & $D+I(n=80)$ & $53 \pm 11$ & $55(44)$ & $79 \pm 11$ & $170 \pm 8$ & $161.9 \pm 11.5$ & $101.6 \pm 4.9$ & $72.9 \pm 9.7$ \\
\hline et $\mathrm{al}^{30}$ & $\mathrm{~L}+\mathrm{HCTZ}(\mathrm{n}=79)$ & $55 \pm 10$ & $55.7(44)$ & $79 \pm 9$ & $170 \pm 8$ & $162.3 \pm 13.1$ & $102.2 \pm 4.8$ & $70.4 \pm 7.4$ \\
\hline \multirow[t]{2}{*}{ All studies } & $D+I(n=643)$ & $53.94 \pm 10.6$ & $57.1(367)$ & $78.6 \pm 12.95$ & $169.9 \pm 9.4$ & $160.6 \pm 13.8$ & $101.7 \pm 4.8$ & $74.4 \pm 9.4$ \\
\hline & $\begin{array}{l}\text { ACEi+HCTZ } \\
(n=629)\end{array}$ & $54.1 \pm 10.8$ & $53.3(335)$ & $77.1 \pm 12.5$ & $169.7 \pm 9.5$ & $160.3 \pm 13.8$ & $101.3 \pm 4.9$ & $73.7 \pm 8.9$ \\
\hline$P$-value* & - & 0.75 & 0.19 & 0.037 & 0.71 & 0.69 & 0.12 & 0.23 \\
\hline
\end{tabular}

Notes: Data are presented as mean and standard deviation for continuous variables or number and percentage for categorical variables. *Comparisons are made between delapril + indapamide and ACEi+HCTZ groups for all four studies. Data presented as mean \pm SD or \% and number.

Abbreviations: ACEi, angiotensin-converting enzyme inhibitors; C, captopril; D, delapril; F, fosinopril; I, indapamide; HCTZ, hydrochlorothiazide; SBP, systolic blood pressure; DBP, diastolic blood pressure; bpm, beats per minute; SD, standard deviation.

D+I combination also experienced a greater reduction in both DBP (95\% CI: $-0.2-2.6 ; P=0.067)$ and SBP $(95 \%$ CI: $-2.0-6.7 ; P=0.19)$ at the end of the study compared to an ACEi+HCTZ combination (Figure 4A and B). It is also worth noting that the extent of the reduction at the end of the study (compared to the 4-week time-point) was maintained for DBP (1.4 mmHg vs $1.24 \mathrm{mmHg}$ ) and improved for SBP $(1.9 \mathrm{mmHg}$ vs $2.3 \mathrm{mmHg})$. No heterogeneity was observed for analysis of $\mathrm{DBP}$ reduction $\left(\mathrm{I}^{2}=0, \mathrm{Q}=2.71\right.$; $P=0.44$ ) (Figure 4A), although moderate heterogeneity was detected in the analysis for $\mathrm{SBP}\left(\mathrm{I}^{2}=63.6, \mathrm{Q}=8.24\right.$; $P=0.04$ ) (Figure 4B).
A

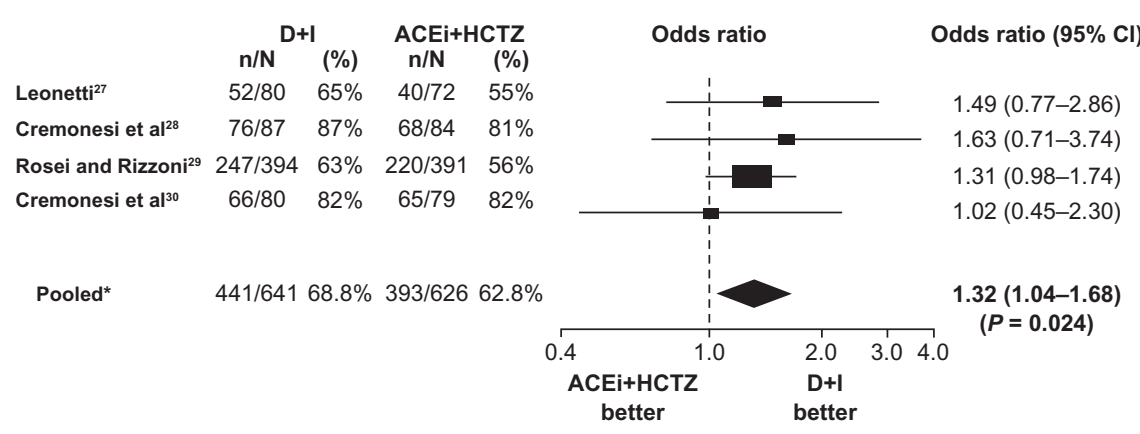

B

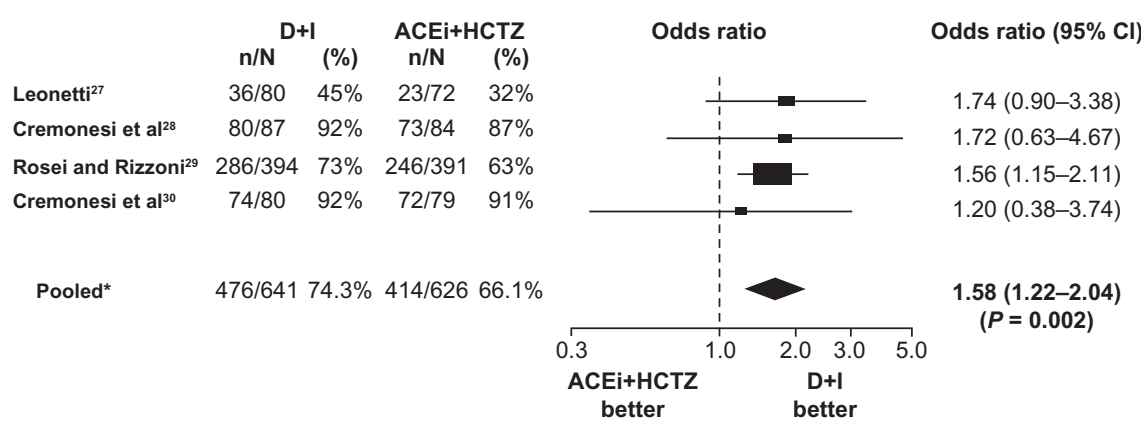

Figure 2 Comparison of the effect of different treatments on blood pressure parameters. The effect of treatment on blood pressure normalizaton (A) and percentage of patient responders are represented by forest plot $(\mathbf{B})$. Effect size presented as odds ratio. $\mathrm{n} / \mathrm{N}$ represent sample sizes.

Notes: (A) \%, proportion of patients with DBP $\leq 90 \mathrm{mmHg} Q$ Cochrane test for Heterogeneity $=0.77(P=0.86)$, df $=3$. *Fixed effect model: no correction within studies and no heterogeneity between studies $\left(I^{2}=0\right)$. (B) \%, proportion of patients with DBP reduction of $\geq 10 \mathrm{mmHg}$ vs baseline (Leonetti: reduction of $15 \mathrm{mmHg}$; Cremonesi, 2002 : responders + normalized). $Q$ Cochrane test for Heterogeneity $=0.34(P=0.95), \mathrm{df}=3$. *Fixed effect model: no correlation within studies and no heterogeneity between studies $\left(\mathrm{I}^{2}=0\right)$. Abbreviations: $\mathrm{Cl}$, confidence interval; DBP, diastolic blood pressure; SBP, systolic blood pressure; SD, standard deviation. 
A

\begin{tabular}{lcccc} 
& & \multicolumn{2}{c}{ D+I } & \multicolumn{2}{c}{ ACEi+HCTZ } \\
& N & Mean (SD) & N & Mean (SD) \\
Leonetti, 1997 & 80 & $13.9(9.2)$ & 72 & $11.0(8.5)$ \\
Cremonesi, 2002 & 87 & $14.0(7.0)$ & 84 & $13.8(7.5)$ \\
Rosei, 2003 & 394 & $12.4(7.6)$ & 391 & $10.5(8.1)$ \\
Cremonesi, 2003 & 80 & $13.6(9.0)$ & 79 & $14.3(8.4)$
\end{tabular}

\section{4-week DBP reduction vs baseline}

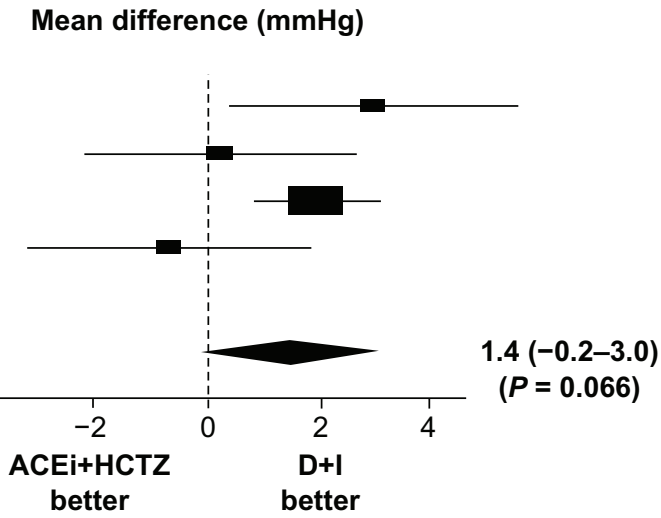

B

\section{4-week SBP reduction vs baseline}

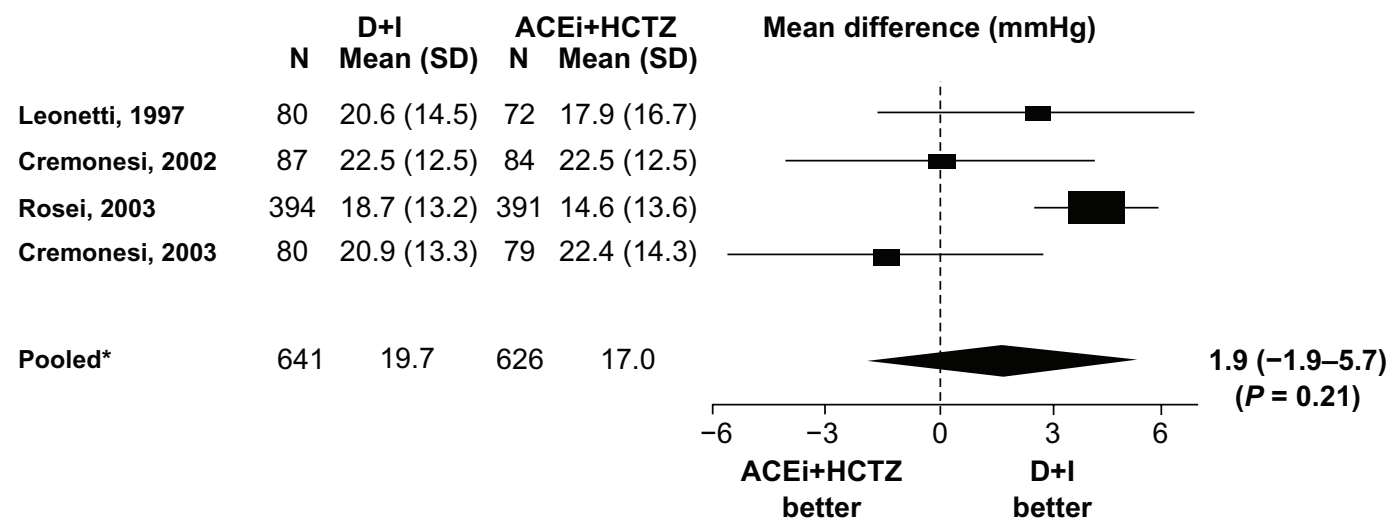

Figure 3 Comparison of the effect of different treatments on reduction of blood pressure at 4 weeks. The effect of treatment on reduction of DBP pressure (A) and reduction of SBP are represented by forest plot $(\mathbf{B})$. Effect size presented as mean difference $(\mathrm{mmHg})$ to baseline value.

Notes: $(A) Q$ Cochrane test for Heterogeneity $=5.79(P=0.12), \mathrm{df}=3$. *Random effect model: no correlation within studies, heterogeneity between studies $\left(\mathrm{I}^{2}=48.2\right)$. (B) Q Cochrane test for Heterogeneity = $7.54(P=0.06)$, $\mathrm{df}=3$. *Random effect model: no correlation within studies, heterogeneity between studies $\left(\mathrm{I}^{2}=60.2\right)$.

Abbreviations: DBP, diastolic blood pressure; SBP, systolic blood pressure; SD, standard deviation.

\section{Safety}

Overall, both treatments were reasonably well tolerated in that the rate of patients reporting at least one adverse event were $10.4 \%$ for $\mathrm{D}+\mathrm{I}$ and $9.9 \%$ for ACEi+HCTZ (Figure $5 \mathrm{~A}$ : $\mathrm{OR}=1.06 ; 95 \%$ CI: $0.73-1.54 ; P=0.62$ ). However, the nature of these events was quite different. When events leading to study treatment withdrawal were considered, the percentage of patients withdrawn in the D+I-treated group was half that of the ACEi+HCTZ-treated group (Figure 5B: $2.3 \%$ vs $4.8 \%$, respectively). The most common AEs reported were: disorders of the respiratory system, ${ }^{29}$ fatigue, malaise, dizziness, dyslipidemia,${ }^{30}$ and cough. ${ }^{27} \mathrm{AEs}$ were not specified in the study by Cremonesi et al. ${ }^{28}$ Pooled analysis of ORs revealed that this difference was statistically significant $(\mathrm{OR}=0.51 ; 95 \% \mathrm{CI}$ : $0.27-0.96 ; P=0.018)$. Low heterogeneity was also noted in both analyses performed (Figure 5A: $\mathrm{I}^{2}=0.0, \mathrm{Q}=2.39, P=0.49$ and Figure 5B: $\mathrm{I}^{2}=0.0, \mathrm{Q}=1.33, P=0.72$ ).

\section{Discussion}

The primary objective of this meta-analysis was to compare the efficacy of D+I to ACEi+HCTZ combinations in the treatment of hypertension. We performed a meta-analysis of four large RCTs and demonstrated that patients with mild-tomoderate hypertension treated with the combination D+I had increased benefit compared to ACEi+HCTZ combinations. More specifically, patients treated with D+I had a higher proportion of having their BP normalized or being defined as responders, compared to ACEi+HCTZ-treated patients. In addition, we also examined the safety of the two drug combinations. Although the rate of AEs was similar for the two treatment groups, patients treated with D+I had significantly less AEs leading to study withdrawal, compared to ACEi+HCTZ-treated patients.

Current international guidelines recommend the use of two or more antihypertensive drugs to reach BP targets. ${ }^{1-3}$ The use of an ACEi combined with a diuretic is an established 
A

\begin{tabular}{lcccc} 
& & D+I & \multicolumn{2}{c}{ ACEi+HCTZ } \\
& N & Mean (SD) & N & Mean (SD) \\
Leonetti, 1997 & 80 & $16.5(7.8)$ & 72 & $14.9(8.2)$ \\
Cremonesi, 2002 & 87 & $18.0(7.1)$ & 84 & $17.0(8.3)$ \\
Rosei, 2003 & 394 & $17.1(7.1)$ & 391 & $15.5(8.6)$ \\
Cremonesi, 2003 & 80 & $17.3(8.2)$ & 79 & $17.9(7.6)$
\end{tabular}

End of study DBP reduction vs basline

\section{Mean difference $(\mathrm{mmHg})$}

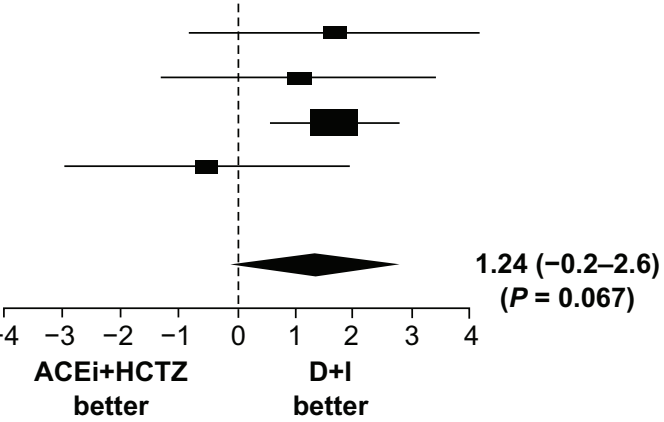

B

End of study SBP reduction vs basline

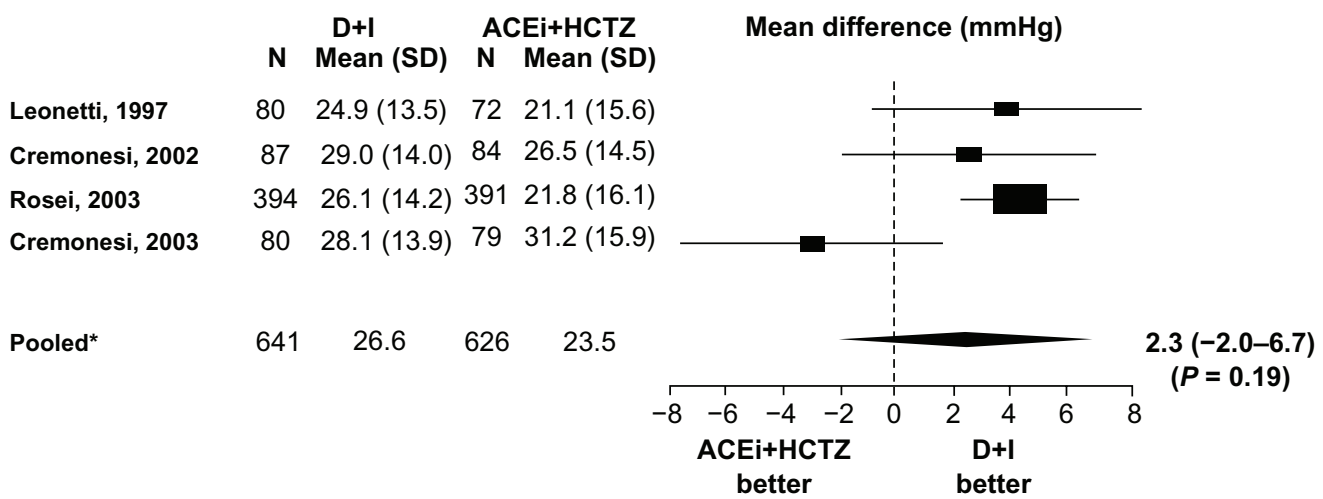

Figure 4 Comparison of the effect of different treatments on reduction of blood pressure at the end of the study. The effect of treatment on reduction of DBP pressure (A) and reduction of SBP are represented by forest plot (B). Effect size presented as mean difference $(\mathrm{mmHg})$ to baseline value.

Notes: $(A) Q$ Cochrane test for Heterogeneity $=2.7 \mathrm{I}(P=0.44)$, df $=3$. *Random effect model: no correlation within studies, heterogeneity between studies $\left(I^{2}=0\right)$. (B) Q Cochrane test for Heterogeneity $=8.24(P=0.04)$, $\mathrm{df}=3$. *Random effect model: no correlation within studies, heterogeneity between studies $\left(I^{2}=63.6\right)$.

Abbreviations: DBP, diastolic blood pressure; SBP, systolic blood pressure; SD, standard deviation.

highly effective combination for the lowering of BP and the currently recommended first-line treatment for hypertension. ${ }^{1-3}$ Recent large RCTs have also demonstrated additional benefit afforded by this combination on recurrent stroke and CV outcomes. ${ }^{35-37}$ The recognized BP-lowering effects of the ACEi/diuretic combination is mainly attributed to the fact that these two drug classes exhibit different mechanisms of action that result in an additive antihypertensive effect. ${ }^{11,12}$ However, it has been suggested that diuretics can exert a potentiating effect on the action of ACEi on the reninangiotensin system, which may also be a relevant factor. ${ }^{38}$ This may provide optimal conditions for ACEi to exert their antihypertensive effects. ${ }^{39}$

An important aspect of the ACEi+diuretic combination is that the diuretic possesses a kaliuretic effect that when the two drugs are coadministered attenuates the potassiumsparing effect of ACEi ${ }^{40,41}$ Moreover, because the dosage of each agent in the combination required to achieve BP control are lower than these same agents given as monotherapy, the tolerability of this combination is particularly favorable..$^{42,43}$ This is particularly relevant for the D+I combination, where their unique and independent modes of action possess additional properties that go beyond their antihypertensive actions. ${ }^{11-15}$

To date, this combination has only been investigated in four head-to-head clinical trials, the trials that were analyzed in the present meta-analysis. ${ }^{27-30}$

It is also worth noting that while the present meta-analysis was limited by the relatively short follow-up periods (4- or 12-week endpoints), two of the studies ${ }^{27,29}$ had follow-up periods of 6 months. In fact, in these two studies, patients treated with $\mathrm{D}+\mathrm{I}$ went on to show greater benefit (in terms of percentage of responders or of normalized patients), at 4 months and again at 6 months. ${ }^{27,29}$ In this respect, our metaanalysis was limited to short-term end-points available in all four trials and may provide an underestimation of the true benefit of the D+I combination over the other ACEi+HCTZ combinations in the long-term. 
A

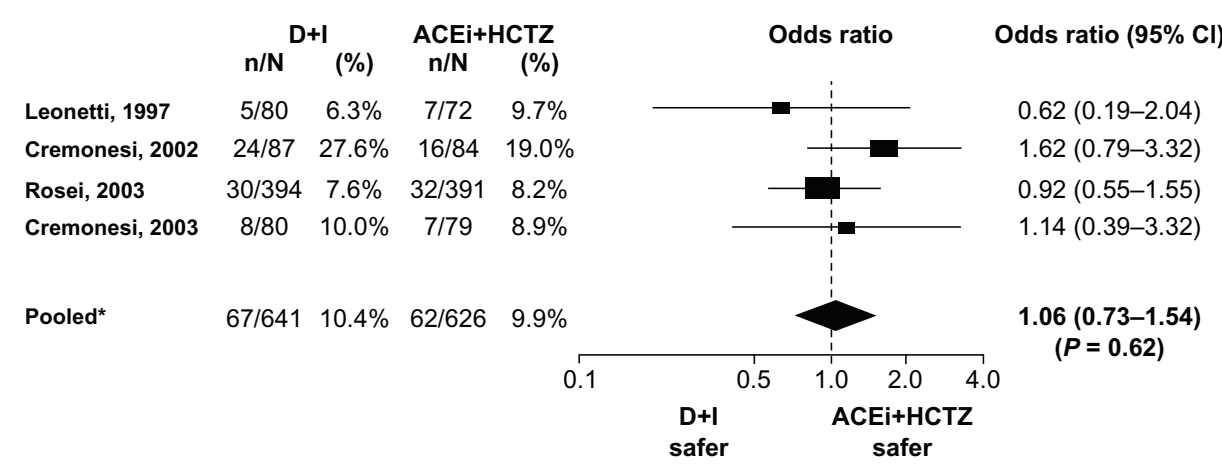

B

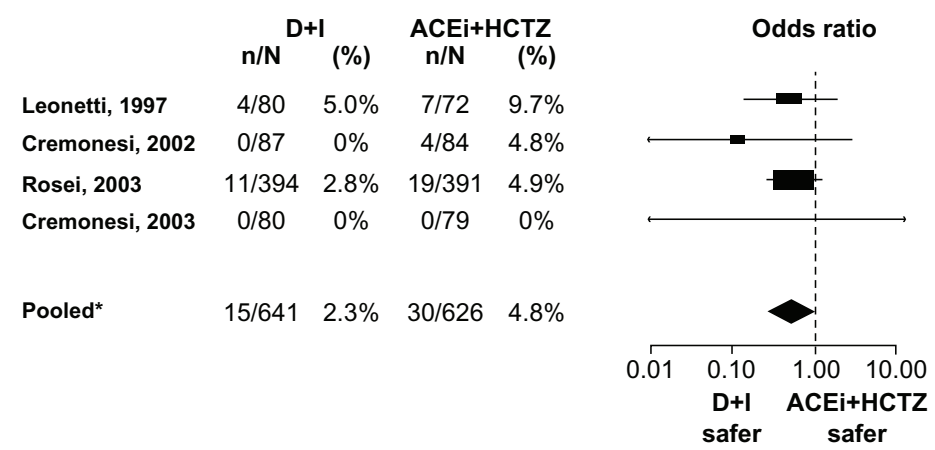

Odds ratio $(95 \% \mathrm{Cl})$

$0.49(0.14-1.74)$

$0.10(0.00-1.93)$

$0.56(0.26-1.20)$

1.00 (0.00-infin)

$0.51(0.27-0.96)$

$(P=0.018)$

Figure $\mathbf{5}$ Comparison between the safety of treatments. The percentage of patients reporting an adverse event $(\mathbf{A})$ and $\%$ of patients withdrawing from study treatment for the two treatments are represented by forest plot (B). Effect size presented as odds ratio.

Notes: $(\mathbf{A}) \%$, proportion of patients with at least one adverse event Cremonesi, 2003: Data provided by the Author $Q$ Cochrane test for Heterogeneity $=2.39(P=0.49)$, $\mathrm{df}=3$. *Fixed effect model: no correlation within studies and no heterogeneity between studies $\left(I^{2}=0\right)$. (B) \%, toxicity leading to withdrawal, $Q$ Cochrane test for Heterogeneity $=1.33(P=0.72), \mathrm{df}=3$. *Fixed effect model: no correlation within studies and no heterogeneity between studies $\left(\mathrm{I}^{2}=0\right)$.

Abbreviation: $\mathrm{Cl}$, confidence interval.

The percentage of normalized $(68.8 \%)$ and responder patients $(74.3 \%)$ are in line with other noncomparative studies that examined the antihypertensive effect of the D+I combination. ${ }^{18,23-26}$ It is also recognized that response rates for this combination typically exceed $80 \%{ }^{42}$ The decrease in BP (DBP and SBP) by D+I at both 4 weeks and at the end of the study was greater than that achieved by the ACEi+HCTZ combination, which supports findings from a recent meta-analysis where indapamide has consistently shown greater efficacy over HCTZ when administered as monotherapy in hypertensive patients. ${ }^{44}$ Our data corroborate these findings further, in that the efficacy conferred by D+I, in terms of BP-reduction, was not just observed over the short-term (4 weeks), but was also maintained over longer periods (1-6 months). This present study also examined the difference in tolerability between patients treated with $\mathrm{D}+\mathrm{I}$ compared to an ACEi+HCTZ. Following meta-analysis, we observed that although no difference was observed in terms of the total number of reported AEs for either treatment combination, the nature of these events were quite different. When the events leading to study treatment withdrawal were considered, patients withdrawing in the D+I-treated group were half those in the ACEi+HCTZ-treated group. Due to the additive effects of the $\mathrm{D}+\mathrm{I}$ combination, hypertension can be well controlled and well tolerated. ${ }^{11,42}$ In addition, delapril has been shown to be better tolerated in terms of frequency of cough, which has been attributed to its weaker bradykinin potentiation $^{45,46}$ and lipid profile. ${ }^{47}$

It is worth noting that in addition to the favorable BPlowering effects and tolerability profile demonstrated in the present meta-analysis, the $\mathrm{D}+\mathrm{I}$ combination is also recognized for its additional or "pleiotropic effects." Evidence indicates that these two drugs in combination exert both renoprotective, antiatherogenic, and cardioprotective effects. ${ }^{13-15}$ Moreover, the low doses and favorable tolerability profile, particularly the indapamide-related metabolic effects, also make this combination suitable for treating patients with diabetes, gout, and hyperlipidemia. ${ }^{11}$ 
It is also recognized that an indapamide-based BPlowering regimen clearly reduces the recurrence of stroke and the incidence of cardiovascular events in patients with cerebrovascular disease, ${ }^{48}$ while a HCTZ-based BP-lowering regimen provided no significant protection against myocardial infarction, stroke, or death. ${ }^{49}$ Actually, the European guidelines states that thiazide diuretics (as well as chlorthalidone and indapamide, but not specifying HCTZ), and other classes of antihypertensive drugs, can adequately lower $\mathrm{BP}$ and significantly and importantly reduce cardiovascular outcomes. ${ }^{3}$ All these drugs are suitable for the initiation and maintenance of antihypertensive treatment either as monotherapy or in some combinations with each other, according to European guidelines. ${ }^{3}$

The present meta-analysis does have some potential limitations. The sample size among the evaluated studies was not equally distributed, since one of the studies accounted for more than half of the total sample size $(n=790)$. To address this, we assessed heterogeneity with the $\mathrm{Q}$ statistic and publication bias was assessed by $\log (\mathrm{OR})$ of sample size weighted by the inverse of the pooled variance. Moderate heterogeneity only appeared in two of the eight analyses we performed, and was not associated with any of the main findings reported. Publication bias was not a problem for any of the analyses performed. Another potential limitation of our analysis was that the dose of indapamide and HCTZ used in the four studies analyzed was not always identical. However, no association was observed between effect size (magnitude of BP reduction) and the dosage administered, which was also confirmed by assessment of heterogeneity.

In conclusion, this is the first meta-analysis available that has systematically examined data reported in head-tohead trials examining the efficacy of D+I compared to an $\mathrm{ACEi}+\mathrm{HCTZ}$ in mild-to-moderate hypertensive patients. The findings derived from the present analysis suggest that treatment with $\mathrm{D}+\mathrm{I}$ could allow a greater proportion of patients reaching target BP values with less patients withdrawing from treatment due to adverse events over an ACEi+HCTZ comparator. Given the fact that a high proportion of hypertensive patients at some stage will require combination therapy to reach target $\mathrm{BP}$ values, ${ }^{2}$ the ACEi/diuretic association may well be considered as a first-line treatment for controlling BP, while also providing both end-organ and $\mathrm{CV}$ protection. ${ }^{1,3}$ The availability of a single-pill fixed-combination D+I for the treatment of essential mild-to-moderate hypertension represents an important step forward.

\section{Contributions}

MC participated in the design of the study, interpretation of data, and writing. GN participated in interpretation of data and writing. CGE performed data analysis and wrote the article. GC participated in the design and interpretation of data. All authors were involved in drafting the manuscript and read and approved the final manuscript.

\section{Acknowledgments}

This study was sponsored by Chiesi Farmaceutici S.p.A., Parma, Italy. The authors thank Luca Cavalieri (Chiesi Farmaceutici) and Lisa Comarella (CROS NT S.R.L., Verona, Italy) for performing meta-analysis.

\section{Disclosure}

Egan CG (on behalf of Primula Multimedia S.R.L., Pisa, Italy) received fees for manuscript preparation. Circelli C, Cremonesi G, and Nicolini G are employees in Chiesi Farmaceutici.

\section{References}

1. Mancia G, De Backer G, Dominiczak A, et al. 2007 ESH-ESC practice guidelines for the management of arterial hypertension: ESH-ESC Task Force on the Management of Arterial Hypertension. J Hypertens. 2007;25:1751-1762.

2. Chobanian AV, Bakris GL, Black HR, et al. The Seventh Report of the Joint National Committee on Prevention, Detection, Evaluation, and Treatment of High Blood pressure: the JNC 7 report. JAMA. 2003;289:2560-2572.

3. Mancia G, Laurent S, Agabiti-Rosei E, et al. Reappraisal of European guidelines on hypertension management: a European Society of Hypertension Task Force document. J Hypertens. 2009;27: 2121-2158.

4. Williams B, Poulter NR, Brown MJ, et al. Guidelines for management of hypertension: report of the fourth working party of the British Hypertension Society, 2004-BHS IV. J Hum Hypertens. 2004;18: 139-185.

5. Ong KL, Cheung BM, Man YB, Lau CP, Lam KS. Prevalence, awareness, treatment, and control of hypertension among United States adults 1999-2004. Hypertension. 2007;49:69-75.

6. Wang YR, Alexander GC, Stafford RS. Outpatient hypertension treatment, treatment intensification, and control in Western Europe and the United States. Arch Intern Med. 2007;167:141-147.

7. Wolf-Maier K, Cooper RS, Kramer H, et al. Hypertension treatment and control in five European countries, Canada, and the United States. Hypertension. 2004;43:10-17.

8. Volpe M, Tocci G, Trimarco B, et al. Blood pressure control in Italy: results of recent surveys on hypertension. J Hypertens. 2007;25: 1491-1498.

9. Ambrosioni E, Leonetti G, Pessina A, et al. Patterns of hypertension management in Italy: results of a pharmacoepidemiological survey on antihypertensive therapy. J Hypertens. 2000;18:1691-1699.

10. Gradman AH, Basile JN, Carter BL, Bakris GL; American Society of Hypertension Writing Group. Combination therapy in hypertension. J Clin Hypertens (Greenwich). 2011;13:146-154.

11. Cavalieri L, Cremonesi G. Delapril plus indapamide: a review of the combination in the treatment of hypertension. Clin Drug Investig. 2007;27:367-380. 
12. Richard V, Joannides R, Henry JP, et al. Fixed-dose combination of perindopril with indapamide in spontaneously hypertensive rats: haemodynamic, biological and structural effects. J Hypertens. 1996;14: 1447-1454.

13. Madkour H, Gadallah M, Riveline B, et al. Indapamide is superior to thiazide in the preservation of renal function in patients with renal insufficiency and systemic hypertension. Am J Cardiol. 1996;22;77:23B-25B.

14. Hernandez A, Barberi L, Ballerio R, et al. Delapril slows the progression of atherosclerosis and maintains endothelial function in cholesterol-fed rabbits. Atherosclerosis. 1998;137:71-76.

15. Circo A, Mangiameli S. The effectiveness of delapril and indapamide in the treatment of patients with arterial hypertension. High Blood Press Cardiovasc Prev. 1994;3(Suppl 4):51-59.

16. Abbou CB. The efficacy and tolerability of indapamide in essential hypertension: a multicentre study in 981 patients. Curr Med Res Opin. 1985;9:494-499.

17. Leonetti G. Tolerability and well-being with indapamide in the treatment of mild - moderate hypertension. Am J Med. 1988;84(Suppl 1B):59-64.

18. Fogari R, Sega R, Zoppi AL, et al. Determination of the optimal dosage of the delapril-indapamide combination in the treatment of mild to moderate arterial hypertension: a multicentre, controlled, double-blind study on parallel group. High Blood Press Cardiovasc Prev. 1994; 3(Suppl 4):26-33.

19. Leenen FHH. Indapamide and vascular reactivity. Drugs Today. 1989;25(Suppl 11):27-35.

20. Bevilacqua M, Vago T, Rogolino A, Conci F, Santoli E, Norbiato G. Affinity of angiotensin I-converting enzyme (ACE) inhibitors for $\mathrm{N}$ - and C-binding sites of human ACE is different in heart, lung, arteries, and veins. J Cardiovasc Pharmacol. 1996;28:494-499.

21. Oka Y. Delapril. Cardiovasc Drug Rev. 1988;6:192-205.

22. Razzetti R, Acerbi D. Pharmacokinetic and pharmacologic properties of delapril, a lipophilic nonsulfhydryl angiotensin-converting enzyme inhibitor. Am J Cardiol. 1995;16(75):7F-12F.

23. Lechi A, Arosio E. Clinical study of the efficacy and tolerability of combined delapril-indapamide in hypertension. High Blood Press Cardiovasc Prev. 1994;3(Suppl 4):39-45.

24. Rappelli A, Dessi-Fulgheri P, Agabiti-Rosei E, et al. Delapril and indapamide combination therapy in hypertensive patients: a double-blind randomized multicenter study. High Blood Press Cardiovasc Prev. 1994:3(Suppl 4):34-38.

25. Acanfora D, Lowenthal DT, Furgi G, et al. The effects of delapril in combination with indapamide on glomerular filtration rate in elderly hypertensive patients. Am J Ther. 1997;4:405-408.

26. Acanfora D, Lowenthal DT, Furgi G, et al. Effects of delapril in combination with indapamide on blood pressure and left ventricular mass in elderly hypertensive patients. Am J Ther. 1998;5:17-23.

27. Leonetti G. Efficacia antiipertensiva dell'associazione delapril-indapamide: "Delapril-Indapamide Multicenter Study" (DIMS) [Anti-hypertensive efficacy of the delapril-indapamide association: "Delapril-Indapamide Multicenter Study” (DIMS)]. Cardiologia. 1997;42:401-406. Italian.

28. Cremonesi G, Cavalieri L, Cikes I, et al. Fixed combinations of delapril plus indapamide vs fosinopril plus hydrochlorothiazide in mild to moderate essential hypertension. Adv Ther. 2002;19:129-137.

29. Rosei EA, Rizzoni D. Evaluation of the efficacy and tolerability of the combination delapril plus indapamide in the treatment of mild to moderate essential hypertension: a randomized, multicentre, controlled study. J Hum Hypertens. 2003;17:139-146.

International Journal of General Medicine

\section{Publish your work in this journal}

The International Journal of General Medicine is an international, peer-reviewed open-access journal that focuses on general and internal medicine, pathogenesis, epidemiology, diagnosis, monitoring and treatment protocols. The journal is characterized by the rapid reporting of reviews, original research and clinical studies across all disease areas.
30. Cremonesi G, Cavalieri L, Bacchelli S, et al. Efficacy and tolerability of delapril plus indapamide versus lisinopril plus hydrochlorothiazide combination treatments in mild to moderate hypertension: a multicentre, randomized clinical study. Curr Ther Res. 2003;64:290-300.

31. Whitehead A. Meta-Analysis of Controlled Clinical Trials. Chichester, NY: John Wiley \& Sons; 2002.

32. Woolf B. On estimating the relation between blood groups and disease. Ann Hum Genet. 1955;19:251-253.

33. Higgins JP, Thompson SG. Quantifying heterogeneity in a meta-analysis. Stat Med. 2002;21:1539-1558.

34. Macaskill P, Walter SD, Irwig L. A comparison of methods to detect publication bias in meta-analysis. Stat Med. 2001;20:641-654.

35. Beckett NS, Peters R, Fletcher AE, Staessen JA, Liu L, Dumitrascu D, et al. HYVET Study Group. Treatment of hypertension in patients 80 years of age or older. N Engl J Med. 2008;358:1887-1898.

36. ADVANCE Collaborative Group. Effects of a fixed combination of perindopril and indapamide on macrovascular and microvascular outcomes in patients with type 2 diabetes mellitus (the ADVANCE trial): a randomised controlled trial. Lancet. 2007;370:829-840.

37. PROGRESS Collaborative Study Group. Randomised trial of perindopril based blood pressure-lowering regimen among 6108 individuals with previous stroke or transient ischaemic attack. Lancet. 2001;358: 1033-1041.

38. Pickering TG. The use of angiotensin converting enzyme inhibitors in combination with other antihypertensive agents. Am J Hypertens. 1991;4(1 Pt 2):73S-78S.

39. Whitworth JA; World Health Organization, International Society of Hypertension Writing Group. 2003 World Health Organization (WHO)/ International Society of Hypertension (ISH) statement on management of hypertension. J Hypertens. 2003;21:1983-1992.

40. Palmer BF. Managing hyperkalemia caused by inhibitors of the reninangiotensin-aldosterone system. N Engl J Med. 2004;351:585-592.

41. Motwani JG. Combining renin-angiotensin-aldosterone system blockade with diuretic therapy for treatment of hypertension. J Renin Angiotensin Aldosterone Syst. 2002;3:72-78.

42. Pessina AC. The clinical use of ACE inhibitors in combination with diuretics: introductory remarks on the fixed combination delapril plus indapamide. High Blood Press Cardiovasc Prev. 1994;3(Suppl 4):1-4.

43. Waeber B. Combination therapy with ACE inhibitors/angiotensin II receptor antagonists and diuretics in hypertension. Expert Rev Cardiovasc Ther. 2003;1:43-50.

44. Baguet JP, Robitail S, Boyer L, Debensason D, Auquier P. A metaanalytical approach to the efficacy of antihypertensive drugs in reducing blood pressure. Am J Cardiovasc Drugs. 2005;5:131-140.

45. Ogihara T, Mikami H, Katahira K, Otsuka A. Comparative study of the effects of three angiotensin converting enzyme inhibitors on the cough reflex. Am J Hypertens. 1991;4:46S-51S.

46. Saruta T, Nishikawa K. Characteristics of a new angiotensin converting enzyme inhibitor: delapril. Am J Hypertens. 1991;4:23S-28S.

47. Ames RP. A comparison of blood lipid and blood pressure responses during the treatment of systemic hypertension with indapamide and with thiazides. Am J Cardiol. 1996;77:12b-16b.

48. Liu L, Wang Z, Gong L, et al. Blood pressure reduction for the secondary prevention of stroke: a Chinese trial and a systematic review of the literature. Hypertens Res. 2009;32:1032-1040.

49. Messerli FH, Bangalore $\mathrm{S}$. Half a century of hydrochlorothiazide: facts, fads, fiction, and follies. Am J Med. 2011;124:896-899.

\section{Dovepress}

A key focus is the elucidation of disease processes and management protocols resulting in improved outcomes for the patient. The manuscript management system is completely online and includes a very quick and fair peer-review system. Visit http://www.dovepress.com/ testimonials.php to read real quotes from published authors. 